\title{
A comparison of phytoplankton assemblages generated by two sampling protocols in a German lowland catchment
}

\author{
Naicheng $\mathrm{Wu}^{*}$, Britta Schmalz and Nicola Fohrer \\ Department of Hydrology and Water Resources Management, Institute for the Conservation of Natural Resources, Kiel University, \\ 24118 Kiel, Germany
}

Received 7 December 2010; Accepted 17 June 2011

\begin{abstract}
Research in the phytoplankton community has become an important part of the overall water-quality monitoring. However, to date studies in small rivers and streams were still scarce and sampling methods were also diverse and not as well developed as in lakes or large rivers. We investigated whether two sampling protocols collected different phytoplankton assemblages within a lowland catchment and, consequently, influenced the outcome of bio-assessment. Data collected from 77 sites by plankton net (PLNET) collection and sedimentation (SEDIM) protocols were analyzed. Median Bray-Curtis (BC) similarity between phytoplankton assemblages generated by the two protocols was $48.5 \%$ (range: $7.5-82.0 \%$ ), and sites with the lowest BC similarities tended to have lower chlorophyll $a(\mathrm{Chl} a)$, water temperature (WT), total suspended solid (TSS) and volatile suspended solid (VSS), but higher channel width and water depth, than other sites with higher BC similarities. Reduced total algal density and biomass, but higher species richness, were observed by the PLNET protocol. However, overall phytoplankton assemblages generated by the two protocols were similar, as indicated by dominant species (paired $t$-test, $P>0.05$ ) and non-metric multidimensional scaling (NMDS) ordination. Nevertheless, from the phytoplankton-based bio-assessment point of view, PLNET protocol was a better method compared with SEDIM protocol because algal data collected by PLNET protocol had higher relationship with environmental variables as indicated by 'Correlation Index' (CoI), Cumulative_ $R^{2}$ and canonical correspondence analysis (CCA).
\end{abstract}

Key words: Algal metrics / canonical correspondence analysis (CCA) / correlation index (CoI) / plankton net (PLNET) / sedimentation (SEDIM)

\section{Introduction}

Phytoplankton, together with benthic algae and macrophytes, constitute the autochthonous primary producers in aquatic ecosystem and form part of the basis of the food web in terms of energy and material input (Hötzel and Croome, 1999). Due to their short life cycle, planktonic algae are sensitive to respond quickly to a broad range of stressors, and thus an ideal indicator for water quality (Domingues and Galvão, 2007; Cabecinha et al., 2009). The investigation of the phytoplankton community has become an important part of the overall waterquality monitoring (Majaneva et al., 2009). From the management decision-making point of view, Jeong et al. (2008) even thought that if an accurate autoregressive model for phytoplankton dynamics was reliable, then forecasting would be possible with only phytoplankton

\footnotetext{
*Corresponding author: nwu@hydrology .uni-kiel .de;
} wunaicheng2003@yahoo.com.cn data instead of monitoring a wide range of limnological changes, which usually has exorbitant costs.

A complete list of species and reliable quantitative data on species densities are of primary importance for bio-assessment development. Only with precise species composition we can get a great deal of community information from different kinds of indices available, like community diversity, growth forms, etc. (Wang et al., 2005). However, the precision obtained in the field may vary greatly due to the differences in sampling methods. Two sampling protocols of phytoplankton were widely used in lakes or large rivers: plankton net (PLNET) collection and sedimentation (SEDIM) method (Hötzel and Croome, 1999; Huang, 2000). PLNET protocol is labor saving, fast, easy to handle and can capture rare species, but allows real nanoplankton to pass through its meshes (Kraatz, 1940; Tangen, 1978). It is thus a preferred method for clean water with low phytoplankton density. In contrast, SEDIM is usually used in water bodies with high phytoplankton density (e.g., Ha et al., 1998; Köhler et al., 
2002; Zhou et al., 2006; Sabater et al., 2008; Friedrich and Pohlmann, 2009; Xu et al., 2009). Nevertheless, in small rivers and streams with relative higher current velocity, the studies on phytoplankton were very scarce (Piirsoo et al., 2008; Sumorok et al., 2009; Centis et al., 2010) and the sampling methods in these systems were also diverse and not as well developed as in lakes or large rivers. For example, Trifonova and Pavlova (2004), Trifonova et al. (2007) and Wu et al. (2007) used SEDIM to explore the riverine phytoplankton community in the river of the Lake Ladoga basin, Russia and the Xiangxi River, China, respectively, while PLNET was employed by Paasche and Ostergren (1980) in the inner Oslofjord, Norway and Plenković-Moraj et al. (2007) in the Drava River, Croatia. Although the above-mentioned methods were both applied in the stream systems, to our knowledge, the influence of two sampling protocols on the outcome of bio-assessment in streams has not been investigated systematically yet. Thus, the main purpose of our study is to determine how phytoplankton sampling protocols may influence bio-assessment.

In this study, we compared phytoplankton assemblages generated from PLNET and SEDIM in a German lowland catchment - the Kielstau catchment. The main aim was to determine whether phytoplankton assemblages generated by the two sampling protocols were related to different environmental variables and therefore might yield different bio-assessment. Our specific objectives were to: (1) compare phytoplankton assemblages collected using PLNET and SEDIM protocols; (2) quantify and compare the relationships between phytoplankton assemblages and environmental variables shown by the two sampling protocols, and (3) compare the relationship of algal metrics, commonly used in bio-assessment, between PLNET and SEDIM protocols.

\section{Methods}

\section{Study area and sites}

The Kielstau catchment is located in northern Germany, with a length of $17 \mathrm{~km}$ and a drainage area of $50 \mathrm{~km}^{2}$. It has its origin in the upper part of Lake Winderatt and is a tributary of the Treene River, which is the most important tributary of the Eider River (Fig. 1). Moorau and Hennebach are two main tributaries within the Kielstau catchment. In addition, various smaller tributaries and water from drainage pipes and open ditches flow into the Kielstau. Sandy, loamy and peat soils are characteristic for the catchment. Land use is dominated by arable land and pasture (Schmalz and Fohrer, 2010). The drained fraction of agricultural area in the Kielstau catchment is estimated at $38 \%$ (Fohrer et al., 2007). The precipitation is $841 \mathrm{~mm} / \mathrm{a}$ (station Satrup, 1961-1990, DWD, 2010) and the mean annual temperature is $8.2^{\circ} \mathrm{C}$ (station Flensburg, 1961-1990, DWD, 2010).

In order to take into account possible interseasonal variations, the study was performed four times in
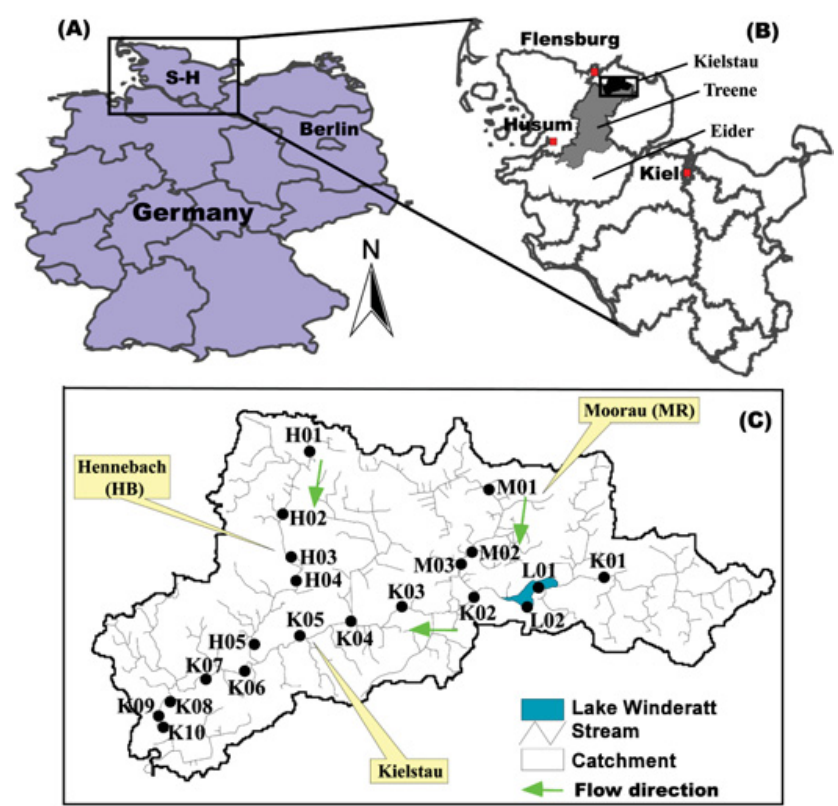

Fig. 1. The location of the Kielstau catchment in SchleswigHolstein state (b), Germany (a; map source: CDC, 2010) and the sampling sites (c). $\mathrm{S}-\mathrm{H}=$ Schleswig-Holstein state; M01-M03 = sampling sites collected from Moorau tributary; $\mathrm{H} 01-\mathrm{H} 05=$ sampling sites from Hennebach tributary; $\mathrm{K} 01-\mathrm{K} 10=$ sampling sites from main stream Kielstau.

November 2008, February 2009, May 2009 and August 2009, respectively. At each date, 20 sites (Fig. 1(c)) along the main stream Kielstau and its tributaries were sampled. Ten sites (K01-K10) were located along the main stream, three (M01-M03) at the Moorau tributary, five (H01H05) at the Hennebach tributary and two (L01 and L02) at Lake Winderatt. Due to some absent samples, we totally collected 77 samples in the four sampling dates.

\section{Sampling methods and primary procedures}

For PLNET collection, at each site and on every sampling date, three replicate samples of known volume subsurface $(5-40 \mathrm{~cm})$ water were taken with a $10 \mathrm{~L}$ bucket, and then the water was filtered through a PLNET. The retained organisms in the PLNET were transferred into glass containers and concentrated to $30 \mathrm{~mL}$. Considering that nets with very fine meshes ( 5 or $10 \mu \mathrm{m}$ ) often filter too little water to provide an adequate algal sample, the mesh size chosen in the present study was $20 \mu \mathrm{m}$ (Paasche and Ostergren, 1980).

Concurrently, the SEDIM protocol was also used at each site. A sample of $1 \mathrm{~L}$ of subsurface $(5-40 \mathrm{~cm})$ river water was taken and fixed in 5\% non-acetic Lugol's iodine solution (Sabater et al., 2008). Forty-eight hours later, the supernatant liquid was removed and the retained organisms were transferred into glass containers. After SEDIM, again samples were concentrated to $30 \mathrm{~mL}$ for further processing.

Besides, the following instream parameters including $\mathrm{pH}$, dissolved oxygen (DO), electrical conductivity 
(COND) and water temperature (WT) were measured in situ by Portable Meter (WTM Multi 340i, Weilheim, Germany). Water depth, channel width and flow velocity (FlowSens Single Axis Electromagnetic Flow Meter, Hydrometrie, Germany) were measured at each site as well. At each site, water samples were also collected for further laboratory analysis.

\section{Chemical variables and chlorophyll a (Chl a) measurement}

The factors including orthophosphate-phosphorus $\left(\mathrm{PO}_{4}-\mathrm{P}\right)$, ammonium-nitrogen $\left(\mathrm{NH}_{4}-\mathrm{N}\right)$, total phosphorus (TP), nitrite-nitrogen $\left(\mathrm{NO}_{2}-\mathrm{N}\right)$, dissolved silicon (Si), nitrate-nitrogen $\left(\mathrm{NO}_{3}-\mathrm{N}\right)$, chloride $\left(\mathrm{Cl}^{-}\right)$and sulphate $\left(\mathrm{SO}_{4}{ }^{2-}\right)$ were measured according to the standard methods DEV (Deutsche Einheitsverfahren zur Wasser-, Abwasser- und Schlammuntersuchung). $\mathrm{PO}_{4}-\mathrm{P}$ and TP were measured using the ammonium molybdate spectrophotometric method (at $880 \mathrm{~nm}$; DIN 1189). We used Nessler's reagent colorimetric method (DIN38 406-E5-1) to measure $\mathrm{NH}_{4}-\mathrm{N}$ concentrations at $690 \mathrm{~nm}$. $\mathrm{NO}_{2}-\mathrm{N}$ was measured by sulphanilamide and $N$-(1-naphthyl)-ethylenediamine method (DIN38 405-D10). Si was measured using molybdosilicate (at $410 \mathrm{~nm}$; DIN38 405-D21) method. $\mathrm{NO}_{3}-\mathrm{N}, \mathrm{Cl}^{-}$and $\mathrm{SO}_{4}{ }^{2-}$ were measured by ion chromatography method (DIN38 405-D19). Dissolved inorganic nitrogen (DIN) was defined as the sum of $\mathrm{NH}_{4}-\mathrm{N}, \mathrm{NO}_{3}-\mathrm{N}$ and $\mathrm{NO}_{2}-\mathrm{N}$, and $\mathrm{N}: \mathrm{P}$ was calculated by DIN:TP. Total suspended solid (TSS) and volatile suspended solid (VSS) were measured according to the standard operating procedure for TSSs analysis (U.S. EPA, 1997). Besides, a known volume of surface water was filtered through Whatman $\mathrm{GF} / \mathrm{C}$ glass-fiber filters for Chl $a$ determination, which was measured spectrophotometrically following $90 \%$ acetone extraction according to APHA (1992).

\section{Algae identification under microscope}

Non-diatom algae were analyzed using a $0.1 \mathrm{~mL}$ counting chamber at a magnification of $400 \times$ (Zeiss Axioskop microscope). Permanent diatom slides were prepared after oxidizing the organic material (by nitric acid and sulphuric acid) according to the methods of Abrantes (1988) and Abrantes et al. (2005) with some modifications. A minimum of 300 valves were counted for each sample using a Zeiss Axioskop microscope at $1000 \times$ under oil immersion. Algae were identified to the lowest taxonomic level possible (mainly species level) according to Simonsen (1987), Round et al. (1990) and LangeBertalot (2000a, 2000b, 2005, 2007) and their densities were expressed as cells. $\mathrm{L}^{-1}$. Total algal biomass (TAB) for each sample was estimated based on multiplication of density data with volume (closest geometric form) supposing specific gravity of $1.00 \mathrm{g.cm}{ }^{-3}$ (Hillebrand et al., 1999; Padisák and Adrian, 1999).

\section{Data calculation and analyses}

Phytoplankton taxon counts were expressed as the proportion of total individuals at each site (relative abundances). Bray-Curtis (BC; relative abundance data) and Jaccard's (presence/absence data) similarities were calculated between PLNET and SEDIM protocols at each site. Sites were then ranked based on their BC similarity and divided into four groups of equal number (low-BC group: $n=20$, all other groups: $n=19$ ). Paired $t$-test was used to compare dominant phytoplankton species collected by PLNET and SEDIM protocols at lotic and lentic sites, respectively. Stream sites were ordinated on the basis of phytoplankton composition (BC similarity as the distance measure) by non-metric multidimensional scaling (NMDS) ordination.

To test the influence generated by PLNET and SEDIM protocols on the outcome of bio-assessment, totally 13 algal metrics, which were commonly used for phytoplankton based bio-assessment, were calculated at each site. These metrics included assemblage diversity measures [e.g., species richness (SpR), Simpson's diversity index (SiD), Shannon-Wiener diversity index [H'] and evenness (Ev)], morphological metrics [\% benthic taxa (BeT), \% mobile taxa (MoT) and \% unattached taxa (UnT)], saprobity index (SaI), Q index (QI), Chlorophyte index (ChI), Pennales index (PeI), total algal density (TAD) and TAB. All the algal metrics were briefly described in Table 1, and all of them (except for TAD) were calculated based on taxa biovolumes. To evaluate the statistical significance of each correlation between biotic metrics and environmental variables, we used 'correlation index' (CoI) and Cumulative_ $R^{2}$ according to Blanco et al. (2007):

$$
\text { Cumulative } \_R^{2}=\Sigma\left(r_{s}^{2}\right)
$$

where $R^{2}$ is the sum of $r_{s}^{2}$ with $r_{s}$ the Spearman's correlation coefficient between a given metric and the environmental variable.

$$
\text { CoI }=\left(\text { Cumulative_ } R^{2} \cdot S\right) / n^{2}
$$

where $\mathrm{CoI}$ is the correlation index for a given metric, $\mathrm{S}$ is the number of $r_{s}$ statistically significant at $P<0.05$, and $n$ is the number of environmental variables evaluated.

CoI ranges from 0 to 1 , while Cumulative_ $R^{2}$ from 0 to $n$, indicating the theoretical minimum and maximum relationship between a given candidate metric and environmental variables, with high values indicating better relationship. Paired $t$-test was also used to compare the differences of CoI and Cumulative_ $R^{2}$ collected by PLNET and SEDIM, respectively.

Moreover, canonical correspondence analysis (CCA) was used to relate algal assemblages generated by PLNET and SEDIM protocols to environmental variables. CCA was chosen because detrended correspondence analyses on the algal data matrices produced longest gradient length of 4.27 and 3.74 for PLNET and SEDIM, respectively (Lepš and Šmilauer, 2003). CCA is a multivariate ordination technique for direct gradient analysis, and it can be used to evaluate species-environment relationships as well 
Table 1. Summary of analyzed algal metrics.

\begin{tabular}{|c|c|c|c|}
\hline Abbreviation & Metric & Description & Reference \\
\hline TAD & Total algal density & Measures of algal numbers per liter & - \\
\hline TAB & Total algal biomass & $\begin{array}{l}\text { Measures of TAB per liter, and is estimated } \\
\text { based on multiplication of density data } \\
\text { with volume (closest geometric form) } \\
\text { supposing specific gravity of } 1.00 \mathrm{~g} . \mathrm{cm}^{-3}\end{array}$ & Hillebrand et al. (1999) \\
\hline $\mathrm{BeT}$ & $\%$ benthic taxa & $\begin{array}{l}\text { Measures of microhabitat traits (pelagic } \\
\text { or benthic life-styles) of taxa }\end{array}$ & $\begin{array}{l}\text { Algal Analysis System (ADAS) } \\
\text { using an attribute file of }\end{array}$ \\
\hline MoT & $\%$ mobile taxa & $\begin{array}{l}\text { Measures of movement capable of taxa in } \\
\text { water or on submerged surface }\end{array}$ & $\begin{array}{l}\text { published values } \\
\text { (van Dam et al., 1994; }\end{array}$ \\
\hline UnT & $\%$ unattached taxa & Measures of algal growth forms & Wang et al., 2005; Porter, 2008) \\
\hline SaI & Saprobity index & Measures of saprobic status of the water & \\
\hline SpR & Species richness & Numbers of specific taxa in each sample & - \\
\hline $\mathrm{SiD}$ & Simpson's diversity index & Measures ecological diversity in the community & \\
\hline $\mathrm{H}^{\prime}$ & $\begin{array}{l}\text { Shannon-Wiener } \\
\text { diversity index }\end{array}$ & & \\
\hline Ev & Evenness & & \\
\hline QI & Q index & $\begin{array}{l}\text { A new evaluation technique of potamo-plankton } \\
\text { for the assessment of the ecological status } \\
\text { of rivers; QI }>4.75=\text { excellent, } \\
4.75-4.50=\text { good, } 4.50-4.00=\text { moderate, } \\
4.00-3.50=\text { poor },<3.50=\text { bad }\end{array}$ & Borics et al. (2007) \\
\hline ChI & Chlorophyte index & The German method to assess rivers by & Mischke and Behrendt (2007) \\
\hline PeI & Pennales index & $\begin{array}{l}\text { phytoplankton with a list of indicator taxa } \\
\text { for routine monitoring in Germany }\end{array}$ & \\
\hline
\end{tabular}

All the algal metrics (except for TAD) are calculated based on algal biomass.

as to derive estimates of the amount of variation in the species data that is explained by measured environmental variables (Reavie et al., 2010). All the algal data were transformed into relative abundance $(0-100 \%)$ before analysis. Because of the large number of rare species, individual taxa chosen for analyses had to occur at $>1$ sample and have a total relative abundance $>0.5 \%$ when all samples were summed; this requirement reduced the number of taxa in the analysis of 31 and 20, respectively for PLNET and SEDIM. Environmental variables with high correlation coefficients $(r>0.60)$ and variance inflation factors (VIF $>20$ ) were excluded in the final CCA analyses ( $\mathrm{Wu}$ et al., 2011). This criterion reduced the number of environmental variables to 11. During CCA, $\log (x+1)$ transformation and down-weighting of rare taxa were applied, and forward selection and Monte Carlo permutations (999 iterations) were used to identify a subset of measured variables that exerted significant and independent effects on phytoplankton assemblages.

NMDS ordination was performed with PRIMER (version 5). Correlation analyses were conducted by STATISTICA 6.0 (version 6.0, StatSoft, Tulsa, Oklahoma), and the data not normally distributed were $\log (x+1)$ transformed prior to analysis. CCA were carried out by CANOCO (version 4.5).

\section{Results}

\section{Environmental characteristics}

River reaches of the study area varied widely in waterquality and habitat characteristics (Tab. 2). For example,
$\mathrm{pH}$ ranged from 6.76 to $9.95($ mean $=7.89)$, DIN ranged from 0.02 to $43.01 \mathrm{mg} . \mathrm{L}^{-1}\left(\right.$ mean $\left.=19.99 \mathrm{mg} . \mathrm{L}^{-1}\right)$, and $\mathrm{TP}$ ranged from 0.04 to $1.30 \mathrm{mg} . \mathrm{L}^{-1}$ (mean $=$ $\left.0.41 \mathrm{mg} . \mathrm{L}^{-1}\right)$. WT averaged $10.56^{\circ} \mathrm{C}\left(0.30-21.50^{\circ} \mathrm{C}\right)$, mean TSS was $11.51 \mathrm{mg} . \mathrm{L}^{-1}\left(1.53-58.40 \mathrm{mg} . \mathrm{L}^{-1}\right)$, mean COND was $604 \mu$ s.cm ${ }^{-1}\left(385-803 \mu \mathrm{s} . \mathrm{cm}^{-1}\right)$. Stream depth ranged from 4 to $81 \mathrm{~cm}$ with an average of $29 \mathrm{~cm}$, and stream width ranged from 0.9 to $4.4 \mathrm{~m}$ with a mean value of $2.2 \mathrm{~m}$.

\section{Phytoplankton assemblage}

A total of 127 taxa (mostly to species levels) were identified from the four sampling dates and two protocols. These taxa belonged to six phytoplankton groups Bacillariophyta, Chlorophyta, Cryptophyta, Cyanophyta, Euglenophyta and Pyrrophyta. Diatoms were predominant with $59.52 \%$ of the total abundance in lotic sites. In the lentic site (L01 and L02), Chlorophyta (88.35\% of the total abundance) was the most abundant group and Cryptophyta (4.99\%), Bacillariophyta (3.96\%), Cyanophyta $(2.43 \%)$, Euglenophyta $(0.26 \%)$ and Pyrrophyta $(0.004 \%)$ followed. One hundred and twentyfive taxa were identified in the PLNET counts and 95 taxa were observed in the SEDIM counts. However, the dominant species with relative abundance $>1 \%$ were similar at both lotic and lentic sites between counts generated by the two sampling protocols (paired $t$-test, $P>0.05$; Tab. 3).

In general, BC similarities ranged from 7.5 to $82.0 \%$ (lower quartile $=36.8 \%$, median $=48.5 \%$ and upper quartile $=60.3 \%$ ), while Jaccard's similarities ranged from 
Table 2. Mean ( \pm 1 SE) values of environmental variables for all sites and for sites grouped by BC similarity between samples collected using PLNET and SEDIM.

\begin{tabular}{|c|c|c|c|c|c|}
\hline Environmental variables & All sites & $\mathrm{BC}>60.3$ & $\mathrm{BC}=48.5-60.3$ & $\mathrm{BC}=36.8-48.5$ & $\mathrm{BC}<36.8$ \\
\hline$\overline{C h l} a\left(\mu \mathrm{g} . \mathrm{L}^{-1}\right)$ & $35.76 \pm 9.64$ & $92.18 \pm 35.91$ & $16.80 \pm 4.02$ & $19.48 \pm 5.72$ & $15.42 \pm 3.38$ \\
\hline $\mathrm{DO}\left(\mathrm{mg} . \mathrm{L}^{-1}\right)$ & $9.21 \pm 0.38$ & $9.98 \pm 0.97$ & $8.92 \pm 0.46$ & $8.52 \pm 0.78$ & $9.38 \pm 0.76$ \\
\hline Channel width (m) & $2.2 \pm 0.11$ & $2.06 \pm 0.21$ & $2.41 \pm 0.22$ & $1.92 \pm 0.19$ & $2.42 \pm 0.25$ \\
\hline Water depth (m) & $0.29 \pm 0.02$ & $0.29 \pm 0.05$ & $0.33 \pm 0.04$ & $0.22 \pm 0.02$ & $0.34 \pm 0.05$ \\
\hline Flow velocity $\left(\mathrm{m} \cdot \mathrm{s}^{-1}\right)$ & $0.17 \pm 0.01$ & $0.10 \pm 0.02$ & $0.22 \pm 0.03$ & $0.18 \pm 0.03$ & $0.17 \pm 0.03$ \\
\hline $\mathrm{pH}$ & $7.89 \pm 0.07$ & $8.02 \pm 0.14$ & $7.81 \pm 0.16$ & $7.77 \pm 0.08$ & $7.97 \pm 0.17$ \\
\hline WT $\left({ }^{\circ} \mathrm{C}\right)$ & $10.56 \pm 0.61$ & $13.15 \pm 1.03$ & $9.82 \pm 1.15$ & $10.9 \pm 1.33$ & $8.37 \pm 1.19$ \\
\hline COND $\left(\mu \mathrm{s} . \mathrm{cm}^{-1}\right)$ & $604.49 \pm 10.59$ & $589.16 \pm 28.13$ & $608.37 \pm 19.9$ & $611.4 \pm 19.63$ & $608.68 \pm 16.95$ \\
\hline TSS (mg. $\left.\mathrm{L}^{-1}\right)$ & $11.51 \pm 1.2$ & $20.97 \pm 3.61$ & $9.29 \pm 1.52$ & $9.34 \pm 1.14$ & $6.55 \pm 0.98$ \\
\hline $\operatorname{VSS}\left(\mathrm{mg} . \mathrm{L}^{-1}\right)$ & $8.61 \pm 0.96$ & $16.01 \pm 3.21$ & $6.07 \pm 0.61$ & $6.91 \pm 0.7$ & $5.55 \pm 0.6$ \\
\hline $\mathrm{NH}_{4}-\mathrm{N}\left(\mathrm{mg} . \mathrm{L}^{-1}\right)$ & $1 \pm 0.17$ & $0.64 \pm 0.21$ & $1.24 \pm 0.36$ & $1.43 \pm 0.47$ & $0.66 \pm 0.15$ \\
\hline $\mathrm{NO}_{3}-\mathrm{N}\left(\mathrm{mg} . \mathrm{L}^{-1}\right)$ & $18.92 \pm 1.17$ & $17.09 \pm 3.18$ & $21.19 \pm 2.29$ & $18.63 \pm 1.93$ & $18.8 \pm 1.87$ \\
\hline $\mathrm{NO}_{2}-\mathrm{N}\left(\mathrm{mg} . \mathrm{L}^{-1}\right)$ & $0.07 \pm 0.01$ & $0.06 \pm 0.01$ & $0.08 \pm 0.02$ & $0.09 \pm 0.02$ & $0.05 \pm 0.01$ \\
\hline DIN (mg.L $\left.{ }^{-1}\right)$ & $19.99 \pm 1.25$ & $17.79 \pm 3.25$ & $22.5 \pm 2.52$ & $20.15 \pm 2.2$ & $19.51 \pm 1.94$ \\
\hline $\mathrm{PO}_{4}-\mathrm{P}\left(\mathrm{mg} \cdot \mathrm{L}^{-1}\right)$ & $0.22 \pm 0.02$ & $0.23 \pm 0.04$ & $0.17 \pm 0.03$ & $0.29 \pm 0.05$ & $0.18 \pm 0.03$ \\
\hline $\mathrm{TP}\left(\mathrm{mg} \cdot \mathrm{L}^{-1}\right)$ & $0.41 \pm 0.03$ & $0.48 \pm 0.06$ & $0.37 \pm 0.05$ & $0.49 \pm 0.06$ & $0.3 \pm 0.03$ \\
\hline $\mathrm{Si}\left(\mathrm{mg} . \mathrm{L}^{-1}\right)$ & $0.23 \pm 0.01$ & $0.22 \pm 0.03$ & $0.23 \pm 0.02$ & $0.24 \pm 0.02$ & $0.23 \pm 0.02$ \\
\hline $\mathrm{Cl}^{-}\left(\mathrm{mg} \cdot \mathrm{L}^{-1}\right)$ & $32.62 \pm 1.04$ & $32.39 \pm 1.6$ & $31.95 \pm 1.3$ & $34.73 \pm 2.28$ & $31.28 \pm 2.83$ \\
\hline $\mathrm{SO}_{4}^{2-}\left(\mathrm{mg} \cdot \mathrm{L}^{-1}\right)$ & $34.71 \pm 1.05$ & $34.63 \pm 2.73$ & $36.2 \pm 1.91$ & $35.57 \pm 2.04$ & $32.39 \pm 1.66$ \\
\hline $\mathrm{N}: \mathrm{P}$ & $76.82 \pm 10.76$ & $77.06 \pm 32.93$ & $91.04 \pm 24.32$ & $52.96 \pm 7.79$ & $87.48 \pm 13.63$ \\
\hline
\end{tabular}

Table 3. Dominant phytoplankton species collected by PLNET and SEDIM in Kielstau catchment at 18 lotic and 2 lentic sites. Paired $t$-test results were also shown.

\begin{tabular}{|c|c|c|c|c|c|}
\hline \multirow[b]{2}{*}{ Species } & \multirow[b]{2}{*}{ Overall } & \multicolumn{2}{|c|}{ Lotic sites } & \multicolumn{2}{|c|}{ Lentic sites } \\
\hline & & PLNET & SEDIM & PLNET & SEDIM \\
\hline \multicolumn{6}{|l|}{ Bacillariophyta } \\
\hline Cocconeis placentula Ehrenberg & 1.51 & 6.73 & 3.96 & 0.07 & 0.02 \\
\hline Cyclotella meneghiniana & 3.02 & 3.77 & 4.43 & 2.47 & 2.33 \\
\hline Fragilaria biceps (Kütz.) Lange-Bertalot & 1.28 & 6.50 & 3.24 & 0.02 & 0.00 \\
\hline Fragilaria crotonensis Kitton & 0.39 & 1.99 & 0.91 & 0.11 & 0.03 \\
\hline Gomphonema olivaceum (Lyngb.) Kütz. & 0.93 & 1.93 & 2.86 & 0.05 & 0.01 \\
\hline Meridion circulare (Grev.) Ag. & 0.51 & 2.71 & 1.29 & 0.00 & 0.00 \\
\hline Navicula cryptocephala Kütz. & 0.96 & 2.64 & 2.83 & 0.04 & 0.00 \\
\hline Navicula ingapirca Lange-Bertalot \& U. Rumrich & 1.29 & 3.34 & 3.80 & 0.14 & 0.01 \\
\hline Navicula viridula (Kütz.) Ehr. & 0.40 & 1.05 & 1.17 & 0.05 & 0.00 \\
\hline Nitzschia sigma (Kütz.) W. Sm. & 0.85 & 3.72 & 2.22 & 0.18 & 0.01 \\
\hline Planothidium lanceolatum (Breb.) Round et Bukhtiyarova & 2.86 & 8.62 & 8.21 & 0.35 & 0.04 \\
\hline Tabellaria flocculosa (Roth) Kütz. & 2.12 & 12.35 & 4.97 & 0.36 & 0.07 \\
\hline Ulnaria ulna (Nitzsch) Comperé & 0.95 & 3.99 & 2.54 & 0.03 & 0.01 \\
\hline \multicolumn{6}{|l|}{ Chlorophyta } \\
\hline Coelastrum sp. & 0.87 & 0.21 & 0.19 & 0.72 & 1.25 \\
\hline Desmodesmus communis (Hegew.) Hegew. & 48.20 & 1.17 & 6.15 & 49.65 & 71.28 \\
\hline Pediastrum duplex Meyen & 7.06 & 0.93 & 0.25 & 26.91 & 9.85 \\
\hline Scenedesmus dimorphus (Turp.) Kütz. & 3.67 & 1.12 & 1.88 & 3.34 & 4.72 \\
\hline \multicolumn{6}{|l|}{ Cryptophyta } \\
\hline Cryptomonas erosa Ehr. & 6.30 & 4.15 & 9.65 & 0.50 & 5.18 \\
\hline \multicolumn{6}{|l|}{ Cyanophyta } \\
\hline Oscillatoria sp. & 1.66 & 2.36 & 4.25 & 0.60 & 0.46 \\
\hline Stigonema sp. & 1.26 & 0.00 & 0.00 & 0.27 & 1.99 \\
\hline \multicolumn{6}{|l|}{ Euglenophyta } \\
\hline Euglena sp. & 6.70 & 9.64 & 20.79 & 0.45 & 0.25 \\
\hline Paired $t$-test & & $t=-0.401$ & $P=0.693$ & $t=-0.391$ & $P=0.700$ \\
\hline
\end{tabular}

Values in tables are relative abundance $(\%)$.

10.5 to $64.9 \%$ (lower quartile $=32.4 \%$, median $=42.1 \%$ and upper quartile $=50.0 \%$ ). Jaccard's similarities were less than $\mathrm{BC}$ similarities in 55 sites, indicating that rare species influenced similarities between PLNET and SEDIM protocols in these sites. The PLNET protocol yielded higher SpR than the SEDIM sampling protocol in 
Table 4. Median (range) of 13 algal indices for samples collected using PLNET and SEDIM for all sites and sites with low values of BC similarity between the two protocols. Coefficients of determination and paired $t$-test are between the two sampling protocols, and bold font indicates statistically significant $(P<0.05)$.

\begin{tabular}{|c|c|c|c|c|c|c|c|}
\hline \multirow[b]{2}{*}{ Algal metrics } & \multicolumn{4}{|c|}{ All sites } & \multicolumn{3}{|c|}{ Low BC sites } \\
\hline & PLNET & SEDIM & $R$ & paired $t$-test & PLNET & SEDIM & $r$ \\
\hline Log (TAD)* & $5.03(3.66-6.19)$ & $5.84(4.75-7.47)$ & 0.58 & 0.000 & $4.91(3.73-5.53)$ & $5.71(5.00-6.57)$ & 0.44 \\
\hline TAB $\left(\mathrm{mg} \cdot \mathrm{L}^{-1}\right)$ & $0.78(0.02-4.24)$ & $5.01(0.08-54.4)$ & 0.60 & 0.000 & $0.50(0.02-2.26)$ & $2.73(0.21-8.80)$ & 0.35 \\
\hline $\operatorname{BeT}(\%)^{*}$ & $46.03(0.42-86.77)$ & $38.09(0-90.28)$ & 0.63 & 0.001 & $41.89(0.66-86.77)$ & $24.35(0-73.03)$ & 0.59 \\
\hline MoT (\%) & $25.35(1.01-92.61)$ & $43.80(0.61-100)$ & 0.63 & 0.000 & $26.92(1.01-90.03)$ & $61.93(19.98-100)$ & 0.67 \\
\hline $\operatorname{UnT}(\%) *$ & $25.08(2.35-98.73)$ & $22.95(0-98.21)$ & 0.82 & 0.183 & $30.30(3.85-89.77)$ & $27.25(0-81.25)$ & 0.66 \\
\hline SaI & $1.04(0.29-2.86)$ & $1.11(0-2.55)$ & 0.43 & 0.208 & $1.15(0.45-2.86)$ & $1.32(0.53-2.55)$ & 0.61 \\
\hline SiD & $7.61(1.58-14.03)$ & $6.35(1.25-15.05)$ & 0.66 & 0.000 & $6.19(1.58-11.87)$ & $4.18(1.59-8.78)$ & 0.31 \\
\hline SpR & $33(17-54)$ & $20(3-41)$ & 0.46 & 0.000 & $35.05(18-54)$ & $15(3-23)$ & 0.57 \\
\hline $\mathrm{H}^{\prime}$ & $2.47(1.01-3.10)$ & $2.09(0.48-3.09)$ & 0.79 & 0.000 & $2.34(1.01-3.03)$ & $1.76(0.71-2.41)$ & 0.68 \\
\hline $\mathrm{Ev}^{*}$ & $0.71(0.28-0.91)$ & $0.71(0.19-0.97)$ & 0.69 & 0.788 & $0.67(0.28-0.82)$ & $0.66(0.38-0.92)$ & 0.66 \\
\hline QI* & $3.67(1.40-4.73)$ & $3.14(1.01-4.96)$ & 0.69 & 0.000 & $3.29(1.76-4.42)$ & $2.67(1.03-3.96)$ & 0.43 \\
\hline ChI (\%) & $13.28(0-79.87)$ & $12.32(0-94.52)$ & 0.67 & 0.635 & $17.12(0-71.08)$ & $10.99(0-63.87)$ & 0.33 \\
\hline $\operatorname{PeI}(\%)^{*}$ & $84.56(0.54-99.47)$ & $78.09(0.84-100)$ & 0.76 & 0.001 & $78.82(4.96-97.05)$ & $69.31(2.55-100)$ & 0.63 \\
\hline
\end{tabular}

Metrics with * are presented in Fig. 3, metric abbreviations are listed in Table 1.

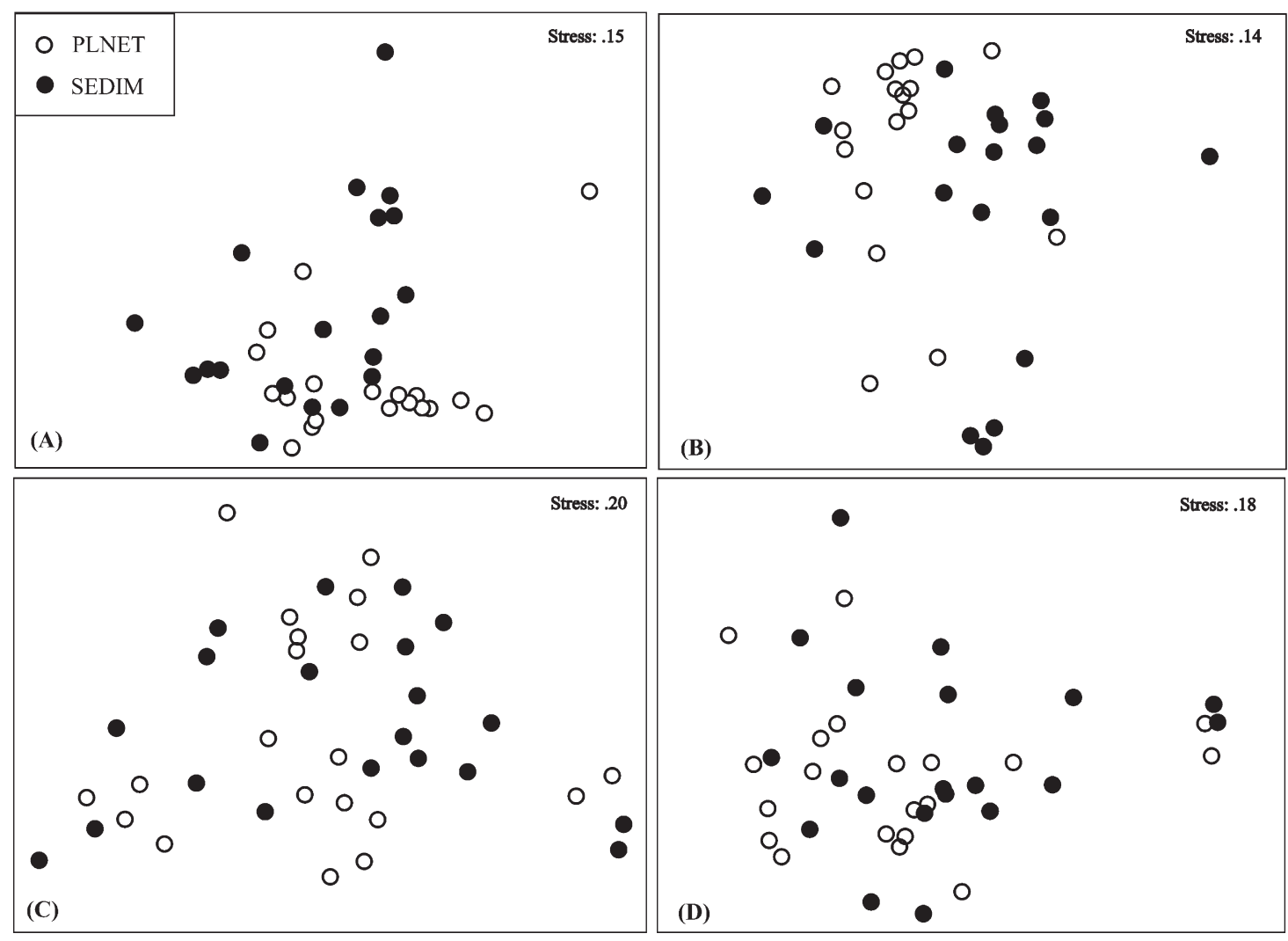

Fig. 2. NMDS ordinations of phytoplankton assemblage collected using PLNET and SEDIM in November 2008 (a), February 2009 (b), May 2009 (c) and August 2009 (d).

72 of 77 sites. Thirty-two taxa identified in the PLNET counts were not found in the SEDIM counts, whereas all taxa observed in the SEDIM counts were found in the PLNET counts. Besides, reduced TAD and biomass (TAB) were observed by PLNET protocol (Tab. 4).

Most sites clustered more closely in the NMDS ordination of PLNET-generated data than those of SEDIM-generated data (Figs. 2(a)-(d))). However, sites of PLNET and SEDIM were not separated along NMDS axis 1 or 2 in the four sampling dates (Figs. 2(a)-(d)), indicating that the two sampling protocols yielded similar phytoplankton assemblages.

\section{Sites with low values of BC similarity}

Phytoplankton assemblages from the subset of sites with the lowest values of BC similarity were examined 

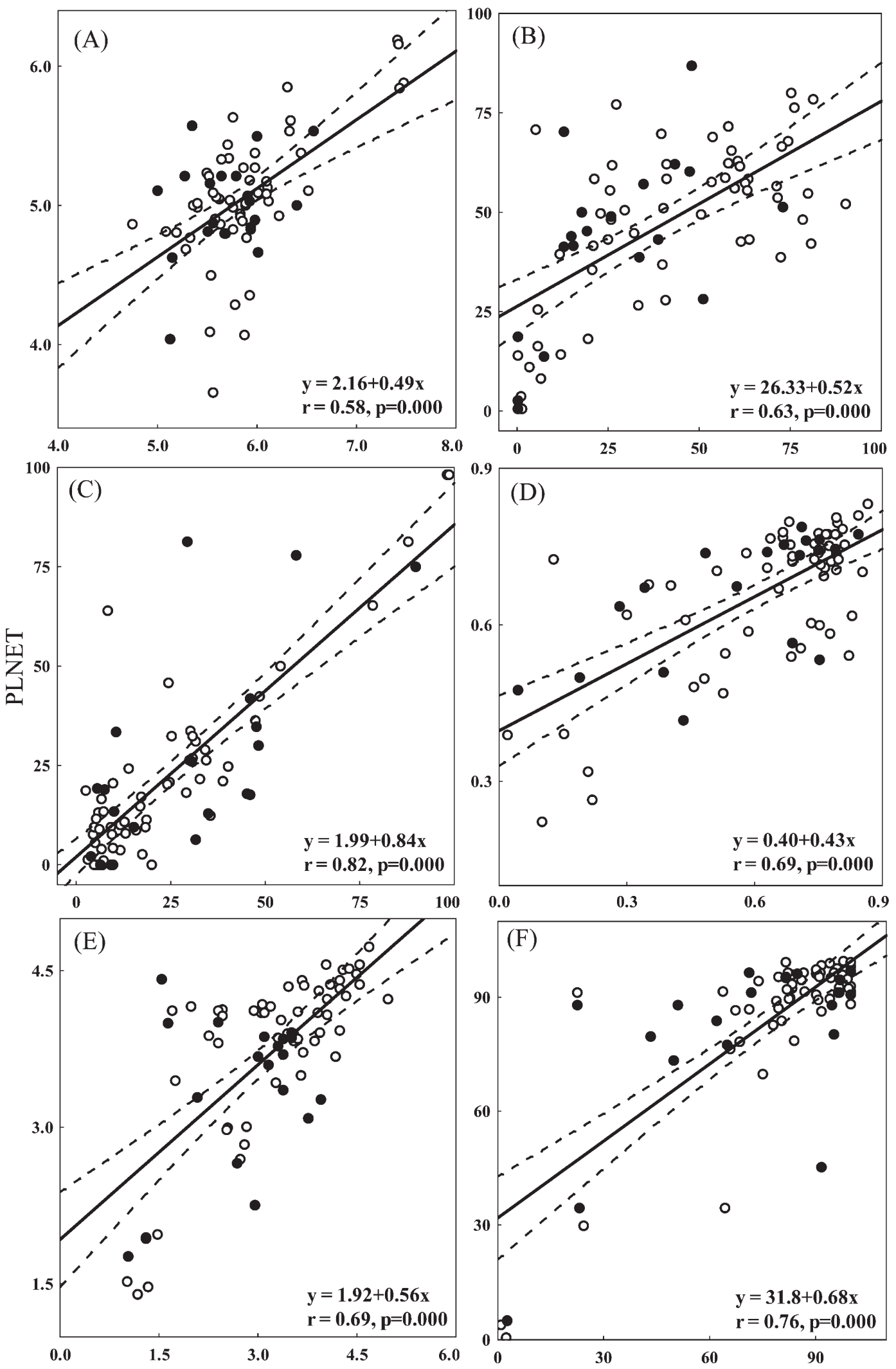

SEDIM

Fig. 3. Relationships between values of total algal densities $[\log (\mathrm{TAD})](\mathrm{a}), \mathrm{BeT}(\mathrm{b}), \mathrm{UnT}(\mathrm{c}), \mathrm{Ev}(\mathrm{d})$, QI (e) and PeI (f) generated by PLNET and SEDIM. Solid circles are sites with the lowest BC values. Solid lines are regression lines and dashed lines indicate the $95 \%$ confidence bands. 
Table 5. Comparisons of CoI values and Cumulative_ $R^{2}$ between PLNET and SEDIM protocols.

\begin{tabular}{lcccc}
\hline \multirow{2}{*}{ Metrics } & \multicolumn{2}{c}{ CoI } & \multicolumn{2}{c}{ Cumulative_R $R^{2}$} \\
\cline { 2 - 5 } Log (TAD) & PLNET & SEDIM & 0.882 & SEDIM \\
TAB (mg.L ${ }^{-1}$ ) & 0.029 & 0.008 & 0.805 & 0.477 \\
BeT (\%) & 0.027 & 0.014 & 0.374 & 0.562 \\
MoT (\%) & 0.009 & 0.010 & 0.451 & 0.392 \\
UaT (\%) & 0.011 & 0.012 & 1.137 & 0.474 \\
SaI & 0.047 & 0.042 & 1.152 & 0.850 \\
SiD & 0.057 & 0.007 & 0.388 & 0.395 \\
SpR & 0.010 & 0.011 & 1.478 & 0.439 \\
H' & 0.098 & 0.010 & 0.822 & 0.387 \\
Ev & 0.048 & 0.010 & 0.248 & 0.416 \\
QI & 0.000 & 0.014 & 0.632 & 0.411 \\
ChI (\%) & 0.021 & 0.005 & 0.546 & 0.299 \\
PeI (\%) & 0.023 & 0.003 & 0.685 & 0.335 \\
Mean & 0.034 & 0.025 & 0.738 & 0.600 \\
Paired $t$-test & 0.032 & 0.013 & & $t=3.071 P=0.009$ \\
\hline
\end{tabular}

Metrics abbreviations are listed in Table 1.

further. Sites were regarded as having a low BC similarity if the values were in the lowest quartile of similarities $(\mathrm{BC}<36.8, n=20)$. For this group, median $\mathrm{SpR}$ was much lower for counts generated by SEDIM than those by PLNET protocol (Tab. 4). Individual values of $\mathrm{SpR}$ were lower by SEDIM protocol than those by PLNET protocol at all the 20 low BC sites. Sites in the low BC group tended to have lower Chl $a$, WT, TSS and VSS, but higher channel width and water depth, than other sites (Tab. 2).

\section{Influences on algal metrics and bio-assessment}

All the 13 algal metrics were significantly correlated between PLNET and SEDIM protocols within all sites $(p<0.05$; Tab. 4, Fig. 3(a)-(f)). Divergence in SpR, TAD, TAB, QI and ChI tended to be greater at sites with the lowest BC values (Tab. 4, Figs. 3(a) and (e)). BC similarity values were only positively related to TAD (log transformed) and TAB ( $r=0.30$ and 0.33 , respectively), but these relationships were statistically significant in all cases $(P<0.05$, Figs 4(a) and (b)).

However, CoI and Cumulative_ $R^{2}$ between algal data collected by PLNET and environmental variables were significantly higher than those of SEDIM, respectively (paired $t$-test, $P<0.05$; Tab. 5). Furthermore, results of CCA relating algal assemblages to environmental variables demonstrated that higher percent of algal variation was explained by PLNET $(38.2 \%)$ than by SEDIM (31.4\%) (Tab. 6).

\section{Discussion}

In our study, the median BC similarity between PLNET and SEDIM protocols was $48.5 \%$, and it is lower than those of previous studies. For example, mean BC similarity between diatom assemblages from different habitats within the same stream sampled multiple times was 68\% (Stevenson and Hashim, 1989). Weilhoefer and

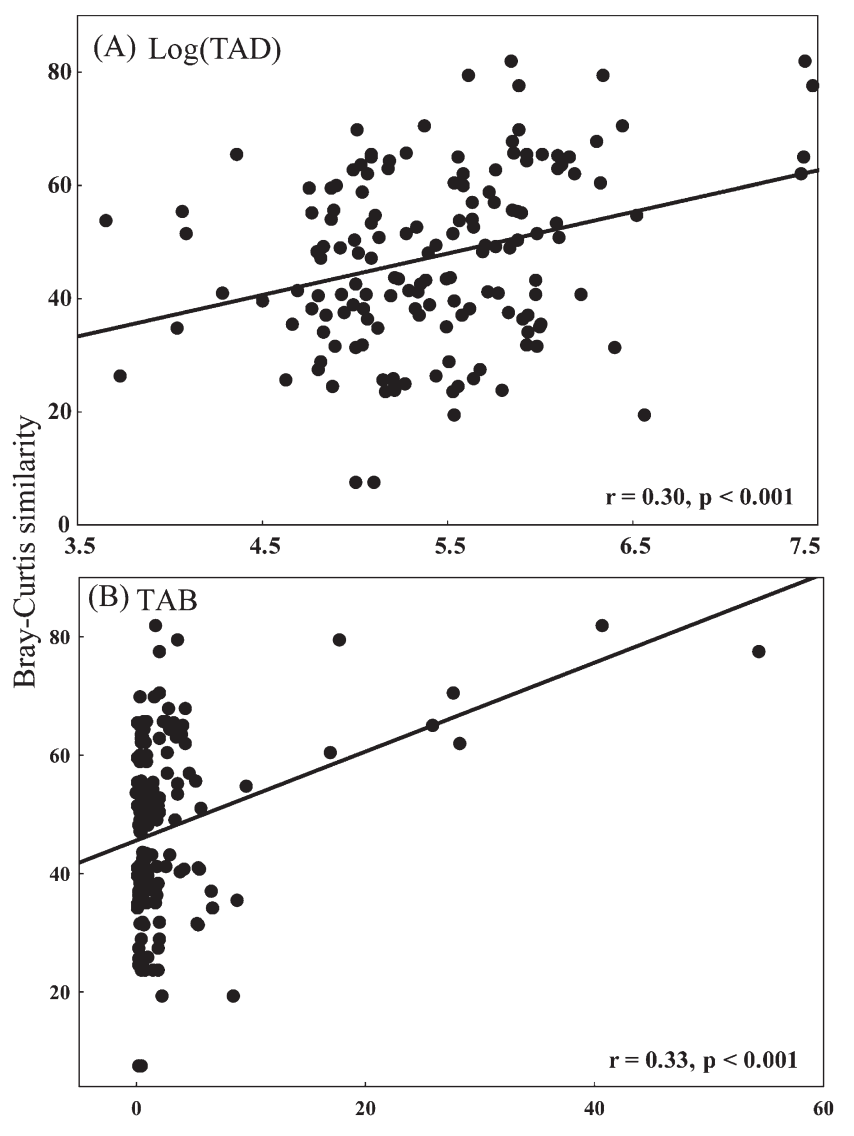

Fig. 4. Regressions of $\mathrm{BC}$ similarity between phytoplankton assemblages generated by PLNET and SEDIM protocols as a function of TAD $[\log (\mathrm{TAD})](\mathrm{a})$ and TAB (b).

Pan (2007), who compared two periphyton sampling protocols in three states of the USA, found a median $\mathrm{BC}$ value of $70 \%$. The potential reason was that the phytoplankton density in our study area was much lower than that in lakes, reservoirs and riverine periphyton. As BC similarity values were significantly positively 
Table 6. Results of canonical correspondence analyses (CCA) relating algal assemblages to environmental variables. Higher percent explained variation indicates stronger algal-environment relationships.

\begin{tabular}{|c|c|c|c|c|c|c|c|c|}
\hline \multirow[b]{2}{*}{ Axes } & \multicolumn{4}{|c|}{ PLNET } & \multicolumn{4}{|c|}{ SEDIM } \\
\hline & 1 & 2 & 3 & 4 & 1 & 2 & 3 & 4 \\
\hline Eigenvalues & 0.130 & 0.122 & 0.066 & 0.037 & 0.126 & 0.111 & 0.068 & 0.033 \\
\hline Species-environment correlations & 0.770 & 0.861 & 0.820 & 0.698 & 0.764 & 0.751 & 0.656 & 0.678 \\
\hline Cumulative percentage variance & & & & & & & & \\
\hline of species data & 12.0 & 23.2 & 29.3 & 32.7 & 10.4 & 19.6 & 25.1 & 27.8 \\
\hline of species-environment relation & 31.4 & 60.9 & 76.8 & 85.7 & 33.2 & 62.3 & 80.1 & 88.7 \\
\hline Sum of all eigenvalues & 1.085 & & & & 1.210 & & & \\
\hline Sum of all canonical eigenvalues & 0.414 & & & & 0.380 & & & \\
\hline$\%$ explained variation in species data & 38.2 & & & & 31.4 & & & \\
\hline
\end{tabular}

correlated with TAD and TAB (Fig. 4), in the low-algae density water bodies, SEDIM sampling protocol is usually not suitable to collect enough species (particularly rare species) to reflect the actual algal characteristics, because it can only collect phytoplankton from 1-L water (compared to 40-60 L of PLNET). Consequently, the similarities between the two sampling protocols were reduced and most of all samples were beyond the $95 \%$ limits (Fig. 3). This was also the reason why PLNET sampling protocol yielded higher SpR than the SEDIM sampling protocol. Because SpR is highly correlated to the volume of sub sample, which has been investigated (Padisák et al., 1999), with increasing volume of sample examined, the number of phytoplankton will increase.

As we used $20 \mu \mathrm{m}$ net for PLNET, theoretically species smaller than $20 \mu \mathrm{m}$ can surpass the PLNET and PLNET protocol would induce reduced TAD and TAB than SEDIM protocol. In the present study, we did find this pattern (Tab. 4), demonstrating the loss of small taxa, as well as TAD and TAB by using PLNET protocol. However, the dominant species generated by the two sampling protocols were similar, as indicated by paired t-test (Tab. 3) and NMDS ordination (Fig. 2). Although the 13 algal metrics were significantly correlated between the two protocols within all sites (Tab. 4 and Fig. 3), paired $t$-test showed that most metrics were significantly different between the two sampling protocols $(P<0.05$; Tab. 4), indicating that the two sampling protocols yielded different information on phytoplankton-based bio-assessment. Furthermore, the PLNET protocol seemed to be a better method than the SEDIM protocol for bio-assessment, as suggested by the results of CoI, Cumulative_ $R^{2}$ and CCA (Tabs. 5 and 6). Many investigators (e.g., Tangen, 1978; Hötzel and Croome, 1999) suggested that the PLNET protocol could only provide qualitative data and should be combined with quantitative methods. Nevertheless, on the other hand, Kraatz (1940) argued that sometimes the PLNET protocol was better for quantitative purposes than the SEDIM protocol. Indeed the SEDIM protocol was less accurate than the PLNET collection because it was based on fewer actual counted specimens and involving more multiplication in the calculation (Kraatz, 1940). From the phytoplanktonbased bio-assessment point of view, the present study was consistent with Kraatz (1940) and found that the PLNET protocol provided more accurate phytoplankton information on algal metrics, although the two sampling protocols generated similar dominant algal species. It must be pointed out that, in rivers, phytoplankton is less used for bio-indicator than other communities, such as periphyton and benthic invertebrates, because planktonic algae are believed to come from either upstream lentic water bodies or the benthos (Hötzel and Croome, 1999). However, the present study found high correlations between algal communities and environmental variables and highlighted the importance of riverine phytoplankton-based bio-assessment.

One of the basic premises of bio-assessment is that the species assemblage has been characterized accurately within the study unit. Both sampling protocols provided similar information about phytoplankton assemblages, but our study did not inform us as to whether the reaches had been sampled adequately. To our knowledge, no published studies have determined the best way to sample a stream reach to represent its phytoplankton assemblage adequately. Several studies have demonstrated that the observed composition and richness of macroinvertebrate and fish assemblages changed as more subsamples were collected within a reach (e.g., Cao et al., 1997, 2002), but no well-developed method existed to determine how many subsamples were enough for representative. Samples' representativeness tended to increase with the number of samples collected, but the stabilization point varied among habitat types (Weilhoefer and Pan, 2007). Thus, phytoplankton-based stream bio-assessment would greatly benefit from further studies on the number of samples needed to characterize phytoplankton adequately in stream reaches with habitat heterogeneities. For instance, multiple samples from different habitats within a reach could be collected and analyzed, respectively, to determine how habitat heterogeneity impacts on descriptors of phytoplankton assemblages. Those data could be used to detect the relationship between the number of samples and $\mathrm{SpR}$ to provide insight into the number of samples necessary to characterize the riverine phytoplankton assemblage.

Acknowledgements. This project was supported financially by German Academic Exchange Service (DAAD). Special thanks to Hans-Jürgen Voss and Dr Honghu Liu for their assistances in the field sampling. We also thank Dr Georg Hörmann for the support in data analyses, Monika Westphal and Bettina 
Hollmann for their help in the laboratory processing. The constructive comments of two anonymous reviewers greatly improved our manuscript.

\section{References}

Abrantes F., 1988. Diatom assemblages as upwelling indicators in surface sediments in Portugal. Mar. Geol., 85, 15-39.

Abrantes F., Gil I., Lopes C. and Castro M., 2005. Quantitative diatom analyses - a faster cleaning procedure. Deep-Sea Res. I, 52, 189-198.

APHA, 1992. Standard methods for the examination of water and wastewater, American Public Health Association, New York

Blanco S., Bécares E., Cauchie H., Hoffmann L. and Ector L., 2007. Comparison of biotic indices for water quality diagnosis in the Duero Basin (Spain). Arch. Hydrobiol. Suppl., 161, 267-286.

Borics G., Várbíró G., Grigorszky I., Krasznai E., Szabó S. and Kiss K.T., 2007. A new evaluation technique of potamoplankton for the assessment of the ecological status of rivers. Arch. Hydrobiol. Suppl., 161 (3-4), 465-486.

Cabecinha E., Cortes R., Cabral J.A., Ferreira T., Lourenço M. and Pardal M.Â., 2009. Multi-scale approach using phytoplankton as a first step towards the definition of the ecological status of reservoirs. Ecol. Indicators, 9, 240-255.

Cao Y., Williams D.D. and Larsen D.P., 2002. Comparison of ecological communities: the problem of sample representativeness. Ecol. Monogr., 72, 41-56.

Cao Y., Williams W.P. and Bark A.W., 1997. Effects of sample size (replicate number) on similarity measured in river benthic Aufwuchs community analysis. Water Environ. Res., 69, 107-114.

CDC, 2010. Centers for Disease Control and Prevention. http:// www.cdc.gov/epiinfo/europe.htm (downloaded 10 October 2010).

Centis B., Tolotti M. and Salmaso N., 2010. Structure of the diatom community of the River Adige (North-Eastern Italy) along a hydrological gradient. Hydrobiologia, 639, 37-42.

Domingues R.B. and Galvão H., 2007. Phytoplancton and environmental variability in a dam regulated temperate estuary. Hydrobiologia, 586, 117-134.

DWD, 2010. Mean values of the precipitation and temperature for the period 1961-1990. www.dwd.de (last accessed 18 June 2010).

Fohrer N., Schmalz B., Tavares F. and Golon J., 2007. Ansätze zur Integration von landwirtschaftlichen Drainagen in die Modellierung des Landschaftswasserhaushalts von mesoskaligen Tieflandeinzugsgebieten. Hydrol. Wasserbewirtschaftung, 51, 164-169.

Friedrich G. and Pohlmann M., 2009. Long-term plankton studies at the lower Rhine/Germany. Limnologica, 39, 14-39.

Ha K., Kim H.W. and Joo G.J., 1998. The phytoplankton succession in the lower part of hypertrophic Nakdong River (Mulgum), South Korea. Hydrobiologia, 369/370, 217-227.

Hillebrand H., Dürselen C.D., Kirschtel D., Pollingher U. and Zohary Y., 1999. Biovolume calculation for pelagic and benthic microalgae. J. Phycol., 35, 403-424.

Hötzel G. and Croome R., 1999. A Phytoplankton Methods Manual for Australian Freshwaters. Land and Water Resources Research and Development Corporation, Canberra.
Huang X.F., 2000. Survey, observation and analysis of lake ecology, Standard Press of China, Beijing.

Jeong K.S., Kim D.K., Jung J.M., Kim M.C. and Joo G.J., 2008. Non-linear autoregressive modelling by temporal recurrent neural networks for the prediction of freshwater phytoplankton dynamics. Ecol. Indicators, 211, 292-300.

Köhler J., Bahnwart M. and Ockenfeld K., 2002. Growth and loss processes of riverine phytoplankton in relation to water depth. Int. Rev. Hydrobiol., 87, 241-254.

Kraatz W.C., 1940. A comparison of plankton counts from the trap-net and water bottle centrifuge techniques. Ohio J. Sci., 40, 151-161.

Lange-Bertalot H., 2000a. Iconographia diatomologica. Annotated diatom micrographs, 7. Diversity-taxonomyidentification. Diatom flora of marine coastes I, Koeltz Scientific Books, Koenigstein, Germany.

Lange-Bertalot H., 2000b. Iconographia diatomologica. Annotated diatom micrographs, 9. Phytogeography-diversitytaxonomy. Diatoms of Andes, Koeltz Scientific Books, Koenigstein, Germany.

Lange-Bertalot H., 2005. Iconographia diatomologica. Annotated diatom micrographs, 15. Taxonomy-biogeographydiversity. Diatoms of Uruguay, Koeltz Scientific Books, Koenigstein, Germany.

Lange-Bertalot H., 2007. Iconographia diatomologica. Annotated diatom micrographs, 18. Diversity-taxonomybiogeography. Tropical diatoms of South America II, Koeltz Scientific Books, Koenigstein, Germany.

Lepš J. and Šmilauer P., 2003. Multivariate analysis of ecological data using CANOCO, Cambridge University Press, New York.

Majaneva M., Autio R., Huttunen M., Kuosa H. and Kuparinen J., 2009. Phytoplankton monitoring: the effect of sampling methods used during different stratification and bloom conditions in the Baltic Sea. Boreal Environ. Res., 14, 313322.

Mischke U. and Behrendt H., 2007. Handbuch zum Bewertungsverfahren von Fließgewässern mittels Phytoplankton zur Umsetzung der EU-Wasserrahmenrichtlinie in Deutschland, WeißenseeVerlag, Berlin. ISBN 978-3-89998-105-6, 88 pp. (in German).

Paasche E. and Ostergren I., 1980. The annual cycle of plankton diatom growth and silica production in the inner Oslofjord. Limn. Oceanogr., 25, 481-494.

Padisák J. and Adrian R., 1999. Biovolumen. In: Tümpling V.W. and Friedrich G. (eds.), Methoden der biologischen wasseruntersuchung 2. Biologische gewässeruntersuchung, Gustav Fischer Verlag, Jena, Chapter 5.1, 334-367.

Padisák J., Krienitz L. and Scheffler W., 1999. Phytoplankton. In: Tümpling V.W. and Friedrich G. (eds.), Biologischen wasseruntersuchung 2. Biologische gewässeruntersuchung, Gustav Fischer Verlag, Jena, Chapter 3.6, 35-53.

Piirsoo K., Pall P., Tuvikene A. and Viik M., 2008. Temporal and spatial patterns of phytoplankton in a temperate lowland river (Emajõgi, Estonia). J. Plank. Res., 30, 1285-1295.

Plenković-Moraj A., Gligora M., Kralj K. and Mustafić P., 2007. Diatoms in monitoring of Drava River, Croatia. Arch. Hydrobiol. Suppl., 161 (3-4), 511-525.

Porter S.D., 2008. Algal attributes: an autecological classification of algal taxa collected by the National Water-Quality Assessment Program. U.S. Geological Survey Data Series 329, http://pubs.usgs.gov/ds/ds329/ (accessed October 2010). 
Reavie E., Jicha T., Angradi T., Bolgrien D. and Hill B., 2010. Algal assemblages for large river monitoring: comparison among biovolume, absolute and relative abundance metrics. Ecol. Indicators, 10, 167-177.

Round F.E., Crawford R.M. and Mann D.G., 1990. The diatoms: biology and morphology of the genera, Cambridge University Press, Cambridge.

Sabater S., Artigas J., Duran C., Pardos M., Romani A.M., Tornes E. and Ylla I., 2008. Longitudinal development of chlorophyll and phytoplankton assemblages in a regulated large river (the Ebro River). Sci. Total Environ., 404, 196-206.

Schmalz B. and Fohrer N., 2010. Ecohydrological research in the German lowland catchment Kielstu. IAHS Publ., 336, 115-120.

Simonsen R., 1987. Atlas and catalogue of the diatom types of Friedrich Hustedt, Volumes 1-3, Catalog. J. Cramer, Berlin.

Stevenson R.J. and Hashim S., 1989. Variation in diatom community structure among habitats in sandy streams. J. Phycol., 25, 678-686.

Sumorok B., Zelazna-Wieczorek J. and Kostrzewa K., 2009. Qualitative and quantitative phytoseston changes in two different stream-order river segments over a period of twelve years (Grabia and Brodnia, central Poland). Inst. Oceanogr., $38,55-63$.

Tangen K., 1978. Nets. In: Sournia A. (ed.), Phytoplankton manual, UNESCO, Norwich, p. 50.

Trifonova I.S. and Pavlova O.A., 2004. Assessment of the trophic state of Lake Ladoga tributaries and the Neva River by phytoplankton. Water Resour., 31, 679-688.

Trifonova I.S., Pavlova O.A. and Rusanov A.G., 2007. Phytoplankton as an indicator of water quality in the rivers of the Lake Ladoga basin and its relation to environmental factors. Arch. Hydrobiol. Suppl., 161 (3-4), 527-549.

U.S. Environmental Protection Agency (U.S. EPA), 1997. Lake Michigan Mass Balance, Methods Compendium, Vol. 3: LMMB 065 (ESS Method 340.2), U.S. Environmental Protection Agency, Great Lakes National Program Office, Chicago.

van Dam H., Mertens A. and Sinkeldam J., 1994. A coded checklist and ecological indicator values of freshwater diatoms from the Netherlands. Netherlands J. Aquat. Ecol., 28, 117-133.

Wang Y.K., Stevenson R.J. and Metzmeier L., 2005. Development and evaluation of a diatom-based index of biotic integrity for the Interior Plateau Ecoregion, USA. J. North Am. Bentholog. Soc., 24, 990-1008.

Weilhoefer C.L. and Pan Y.D., 2007. A comparison of diatom assemblages generated by two sampling protocols. J. North Am. Bentholog. Soc., 26, 308-318.

Wu N.C., Schmalz B. and Fohrer N., 2011. Distribution of phytoplankton in a German lowland river in relation to environmental factors. J. Plankt. Res., 33, 807-820.

Wu N.C., Tang T., Zhou S.C., Fu X.C., Jiang W.X., Li F.Q. and Cai Q.H., 2007. Influence of cascaded exploitation of small hydropower on phytoplankton in Xiangxi River. Chin. J. Appl. Ecol., 18, 1091-1096.

Xu Y.Y., Cai Q.H., Ye L., Zhou S.C. and Han X.Q., 2009. Spring diatom blooming phases in a representative eutrophic bay of the Three-Gorges Reservoir, China. J. Freshw. Ecol., 24, 191-198.

Zhou G.J., Kuang Q.J., Hu Z.Y. and Cai Q.H., 2006. Study on the succession of algae and the trend of waterbloom occurred in Xiangxi Bay. Acta Hydrobiol. Sin., 30, $42-46$. 